\title{
A valorização do magistério como uma dimensão da qualidade da educação: uma mirada sobre o debate sindical ${ }^{*}$
}

Andréa Barbosa Gouveia

Marcos Alexandre dos Santos Ferraz

\section{Resumo}

A definição da valorização docente como princípio constitucional pode ser considerada uma conquista do movimento sindical docente e, desde então, a disputa pelo conteúdo da valorização é um desafio para a política pública, a construção teórica do campo de políticas educacionais e os debates sobre a qualidade do ensino. A pauta corporativa e classista, que está na gênese do movimento sindical, impõe desafios à forma de tematizar as políticas de valorização e as discussões sobre qualidade. Para olhar esse fenômeno, o presente artigo apresenta uma análise documental das posições da Confederação Nacional de Trabalhadores da Educação (CNTE) expressas nas resoluções dos Congressos de 1991 e 2017. A partir das discussões sobre a ambiguidade entre profissionalização, proletarização e semiprofissão, conclui-se que o debate sindical reorganiza a disputa ao redor das políticas de valorização como uma dimensão da qualidade da educação e impõe novos debates ao campo científico.

Palavras-chave: política educacional; valorização docente; sindicalismo docente.

O artigo apresenta um recorte da pesquisa CNTE, FENPROF e as disputas da política educacional: a luta de professores brasileiros e portugueses no período democrático recente, financiada pelo Edital Universal de 2016 do Conselho Nacional de Desenvolvimento Científico e Tecnológico (CNPq). 


\section{Abstract \\ Teacher appreciation as a dimension of education quality: a perspective on union debate}

Making teacher appreciation a constitutional principle can be perceived as a teacher union movement achievement; since then, a dispute over the content of appreciation is a challenge for public policy, for the theoretical development of the educational policies field and for the debates on quality in teaching. The corporate and class agenda, figuring at the roots of the union movement, presents challenges on how to approach appreciation policies and discussions on quality. To observe this phenomenon, this paper develops a documentary analysis of the positions of the Confederação Nacional de Trabalhadores da Educação (National Confederation of School Workers, acronymed CNTE) expressed in their 1991 and 2017 gatherings resolutions. From the discussions regarding the ambiguity among professionalization, proletarianization, and semi-profession, it was concluded that union debates reorganize disputes around the appreciation policies as a dimension of education quality and encourage new debates at the scientific field.

Keywords: educational policies; teacher appreciation; teacher unionism.

\section{Resumen \\ La valorización de la profesión docente como una dimensión de la calidad de la educación: una mirada al debate sindical}

La definición de la valorización docente como principio constitucional puede ser considerada una conquista del movimiento sindical docente y, desde entonces, la disputa por el contenido de la valorización es un reto para la política pública, la construcción teórica del campo de políticas educativas y los debates sobre la calidad de la enseñanza. La agenda corporativa y de clase, que se encuentra en la génesis del movimiento sindical, impone retos sobre cómo enfocar las políticas de valorización y las discusiones sobre calidad. Para observar este fenómeno, el presente artículo hace un análisis documental de las posiciones de la Confederación Nacional de los Trabajadores de la Educación (CNTE) expresadas en las resoluciones de los Congresos de 1991 y 2017. Desde las discusiones sobre la ambigüedad entre profesionalización, proletarización y semiprofesión, se concluye que el debate sindical reorganiza la disputa en torno a las políticas de valorización como una dimensión de la calidad de la educación e impone nuevos debates al campo científico.

Palabras clave: políticas educativas, apreciación docente, sindicalismo docente. 


\section{Introdução}

A definição da valorização docente como um princípio na Constituição de 1988 foi conquista dos movimentos sociais, com destaque para o ascendente movimento sindical docente, e, desde então, a disputa pelo conteúdo da valorização é um desafio para a política pública e para a construção teórica do campo de políticas educacionais. Ainda que seja possível reconhecer dimensões consolidadas na literatura sobre valorização, como formação, carreira, condições de trabalho e remuneração, é também possível considerar que a abrangência e as consequências de cada um desses elementos continuam na disputa e podem se articular tanto às perspectivas centradas nos processos educacionais e nas suas condições de qualidade (Camargo et al., 2006; Dourado; Oliveira, 2009) quanto àquelas que absolutizam os resultados escolares como única dimensão legítima de qualidade (Hanushek, 2011).

Esses dois polos têm consequências diferenciadas em termos de compreensão da relação entre qualidade de ensino e valorização de professores. Um exemplo dessas consequências são os embates pela alocação dos recursos para a educação. A depender de como a relação seja entendida, a tensão pela legitimidade dos investimentos em pessoal no âmbito do orçamento público amplia-se. A literatura sobre custos educacionais (Verhine, 2005; Pinto, 2006; Alves et al., 2019) explicita a centralidade dos custos com pessoal na compreensão dos orçamentos da educação, o que leva a questão a ser um tema essencial no âmbito da política educacional, dado o quantitativo de professores necessários ao funcionamento do sistema. Considerando isso, o artigo mostrará a articulação entre qualidade e valorização docente na agenda sindical pós-1988, tendo como foco empírico as posições da Confederação Nacional de Trabalhadores da Educação (CNTE) expressas em congressos da entidade.

O pressuposto inicial é o de que a abordagem da valorização do professor como condição subordinada à melhoria da qualidade de ensino pode reforçar perspectivas pragmáticas de carreira que se encontram com as formas de gestão por resultados e a necessidade de políticas diferenciadas de remuneração. Por sua vez, a dimensão da valorização profissional, tendo em conta a qualidade de vida do trabalhador (Grochoska, 2015), permite o respeito aos sujeitos do processo educacional e uma leitura mais contextualizada da vida escolar, em que a ação dos diferentes atores contribui para o desenvolvimento humano dos estudantes, entendendo qualidade de ensino como desenvolvimento societário e não apenas mensuração técnica.

Para o debate empírico, tomam-se as resoluções de congressos nacionais da CNTE. Dado o federalismo brasileiro, a divisão de responsabilidades entre os diferentes sistemas de ensino municipais, estaduais e distrital implica também organização múltipla dos trabalhadores da educação. Justifica-se a escolha da CNTE pela representatividade dessa entidade no âmbito das redes públicas de educação básica no Brasil. A CNTE, nesse cenário, congrega 25 sindicatos estaduais, do Distrito Federal e mais sindicatos municipais, totalizando 52 entidades filiadas (CNTE, 2020). 
Essa condição não significa que seus documentos esgotem todas as questões em curso nas disputas da categoria, mas são a mais importante fonte para um estudo nacional sob a ótica politicamente organizada dos profissionais.

Pode-se afirmar que a base da CNTE congrega acima de 60\% dos docentes da educação básica pública brasileira. Tal projeção é possível, pois, com exceção do Sindicato Estadual dos Profissionais de Educação do Rio de Janeiro (Sepe-RJ), todos os sindicatos das redes estaduais estão filiados à Confederação. Em relação aos sindicatos que representam as redes municipais do Mato Grosso do Sul, todos estão na base da entidade nacional, visto que são filiados à Federação dos Trabalhadores em Educação de Mato Grosso do Sul (Fetems), filiada à CNTE. Por fim, ainda que o número de sindicatos de redes municipais filiado diretamente à CNTE seja pequeno, a filiação se concentra entre os sindicatos de capitais e grandes cidades, portanto, as grandes redes municipais.

Trabalhou-se, inicialmente, com o conjunto das resoluções do período de 1990 a 2017, ${ }^{1}$ mediante a análise temática (Lapadat, 2010) de um tópico específico delas - o plano de lutas educacionais. Quando esse subitem não estava na estrutura do documento, os pesquisadores categorizaram os tópicos do plano de lutas por temáticas, incluindo, aqui, as que podem ser identificadas como lutas corporativas e lutas educacionais. A separação entre lutas corporativas e educacionais é realizada, no presente texto, como recurso metodológico típico ideal, dividindo em polos cognitivos aquilo que, na realidade, é um continuum repleto de gradações. Como luta corporativa entende-se aquela que se legitima pela associação orgânica de interesses concretos das atividades profissionais, no sentido em que Incisa (1992) e Reis (1995) definem corporativismo. Neste estudo, é explicitada como luta por carreira, remuneração, jornada e condições de trabalho. Assim, ainda que as lutas corporativas sejam materializadas em políticas educacionais, neste artigo, a expressão "lutas educacionais" foi metodologicamente reservada para aquelas que não derivam da associação orgânica de interesses profissionais, englobando, portanto, as lutas por projeto pedagógico, formação docente, gestão e financiamento da educação.

Em virtude do volume de documentos nesses 30 anos de história da CNTE, apresenta-se um panorama geral da categorização e uma análise mais focalizada das resoluções específicas dos anos de 1991 e 2017, como amostra do debate sindical. Justifica-se essa escolha, pois: no ano de 1991, ocorreu o primeiro congresso da CNTE; em 1990, houve o Congresso de Unificação, mas este teve como foco a organização da entidade; e o Congresso de 2017 foi o último realizado.

Além desta introdução, o artigo está organizado em três partes. A primeira expõe uma síntese de como o campo dos estudos em políticas educacionais vincula valorização do magistério e qualidade da educação. A segunda traz uma abordagem descritiva dos documentos da CNTE. Por fim, apresentam-se as considerações finais.

\footnotetext{
${ }^{1}$ As resoluções de toda a série histórica foram disponibilizadas pela CNTE, porém, na digitalização dos originais, as resoluções de 1995, 2002 e 2008 contemplaram apenas os cadernos de tese. Neste artigo, optou-se por trabalhar com as resoluções finais, portanto, esses três anos não estão incluídos.
} 


\section{A valorização dos professores e a qualidade da educação: alguns elementos da literatura}

Os debates sobre qualidade da educação são marcados pelo reconhecimento da polissemia do termo (Dourado; Oliveira, 2009), que passa pela definição do que é qualidade e do que a compõe em diferentes contextos históricos e sociais. Uma primeira delimitação está no marco legal para a compreensão da qualidade como uma dimensão do direito à educação (Cury, 2014) e o reconhecimento da importância de essa dimensão ser proclamada como um princípio de organização da educação nacional no arcabouço legal brasileiro, a partir da Constituição de 1988.

$\mathrm{Na}$ chave explicativa da qualidade como direito - e não como processo de seleção meritocrática -, a centralidade do debate sobre os professores se apresenta, ainda que não esgote os elementos, com uma força constitutiva do fenômeno educacional. Nos termos de Cury (2014, p. 1060), "sem uma dignificação salarial, sem uma formação continuada, a avaliação de desempenho, legalmente prevista, tenderá mais para uma visão punitiva do que para a reiterada melhoria". Os elementos de qualidade, relativa ao trabalho docente, indicados por Cury implicam tanto políticas dos sistemas de ensino quanto ações internas a cada escola. Dourado e Oliveira (2009, p. 209) delimitam que o debate sobre qualidade da educação precisa considerar a articulação entre o plano do sistema de ensino, o da escola, o do aluno e o dos professores; sobre a questão no plano do professor, articulam as ideias de formação com as de "profissionalização e ação pedagógica".

O tema da profissionalização docente não é novo. Diversos autores (Tenti Fanfani, 2005; Oliveira, 2010; Mehta, 2013; Nóvoa, 2017; 2019) problematizam, no campo da sociologia das profissões, os dilemas que a docência enfrenta para se caracterizar como profissão com status reconhecido a partir de elementos tradicionais como: o controle sobre seu próprio trabalho ou o domínio técnico de seu saber; o controle sobre o acesso à profissão e a discricionariedade na execução do trabalho ou, em outros termos, a autonomia. As tensões em torno da existência ou não desses elementos levam Mehta, por exemplo, a definir o magistério como "semiprofissão" ao analisar a vida nas escolas americanas. Ainda que o autor se refira a um caso específico, alguns elementos do debate ajudam a refletir sobre o cenário brasileiro. Para Mehta (2013), o magistério pode ser definido como semiprofissão, na medida em que os professores não desenvolveram o mesmo poder das profissões tradicionais devido a razões relacionadas a:

1) alta demanda de quadros, o que impede um controle sobre quem entra na profissão;

2) falta de uma base codificada de conhecimento;

3) grande presença feminina e atendimento de crianças, que nas disputas sociais enfraquecem o status.

Cada um desses elementos é passível de debates próprios. Os dilemas sobre o conteúdo do trabalho docente e, por consequência, sobre formação relacionam-se 
com os embates contra a padronização de resultados escolares e a necessidade de formatar a ação docente para que ela responda aos objetivos restritos de exames em larga escala. Essa questão foi motivo de ampla polêmica durante a tramitação da proposta da Base Nacional Comum Curricular (Hypolito, 2019) e encontra-se com os argumentos de que é preciso medir os resultados dos estudantes como forma de controlar o que se faz na escola. Mas não é apenas nessa direção que a alegação de Mehta pode ser entendida. O controle sobre o que é a natureza da profissão pode gerar debates acerca de uma codificação feita pelos próprios profissionais, o que pode se encontrar mais com a questão da autonomia e com a complexidade vislumbrada por Cury (2014) e por Dourado e Oliveira (2009) no reconhecimento da importância do trabalho docente na efetivação da qualidade da educação.

A perspectiva indicada por Mehta (2013) de que o magistério não tem uma base de conhecimento codificada de maneira suficiente, ainda que discutível, ajuda a reafirmar a necessidade da formação de professores em cursos de licenciatura. Por outra ótica, Oliveira (2010) percebe essa insuficiência em uma dimensão de ambiguidade entre o profissionalismo e a proletarização na constituição da identidade profissional docente. Nessa conjugação, a autora abre caminho para compreender a sindicalização como aríete do processo de valorização profissional, mesmo que, em termos da sociologia das profissões, possa parecer uma contradição conceitual.

No caso brasileiro, a permanência na legislação da ideia de que é possível admitir menos que a formação em nível superior, quando se trata da educação infantil e dos anos iniciais do ensino fundamental (Brasil. Lei $n^{\circ}$ 9.394, 1996), e, mais recentemente, a inclusão na Lei de Diretrizes e Bases da Educação Nacional (LDB) da figura do notório saber na educação profissional (Brasil. Lei $n^{\circ} 13.415,2017$ ) compõem parte do problema de que a qualidade da formação pode ser relativizada, em um sentido de intensificação da proletarização e perda da codificação de conhecimento específico. Afirmar a formação de qualidade exige a determinação das licenciaturas como lócus de formação definitivo e condições para que esse percurso seja feito por todos os profissionais em atuação.

A questão do recrutamento massivo de quadros é um paradoxo, pois a alta demanda se articula com a necessária expansão da educação como direito. Portanto, é parte da qualidade da educação a sua forma ampla e democrática. Isso tem implicação direta nos orçamentos públicos, que precisam garantir patamar de investimento compatível com o tamanho do compromisso nacional. A medida para essa relação, conforme estabelecido no Plano Nacional de Educação de 2014, foi a equiparação da média da remuneração de professores à de profissionais de mesma formação (Brasil. Lei no 13.005, 2014). Essa não é uma relação simples, pois a questão da jornada precisa ser considerada, uma vez que múltiplos vínculos não significam ampliação da média de remuneração. Os professores, ao necessitarem se submeter ao trabalho em mais de uma rede, ficam sujeitos a diferentes planos de carreira e trajetórias em seu interior. Ainda que haja dificuldade de medida, o princípio de isonomia com outros profissionais possuidores de ensino superior é salutar para pensar a valorização profissional. 
Outro elemento que se pode considerar em diálogo com Mehta (2013) é a recorrente desigualdade entre professores por área de atuação. Diferentes estudos reiteram que os docentes brasileiros continuam sendo pagos pela estatura dos estudantes (Pinto, 2006; Barbosa, 2014). A desigualdade salarial entre os professores do ensino médio e os da educação infantil é resultado de uma aceitação social de que o trabalho com crianças pequenas é mais fácil, assim como dos processos de feminização e feminilização dessa etapa de ensino (Yannoulas, 2011) e da concentração dos professores da educação infantil nas redes municipais, que pagam as menores remunerações.

Pensar as relações entre qualidade e valorização docente implica enfrentar esse conjunto de condições e reafirmar a perspectiva mais ampla da atividade docente como profissão que exige condições de trabalho específicas para o desenvolvimento da atividade, que requer interação entre sujeitos e regularidade. Uma vista sobre a agenda sindical, naquilo que expõe a ambiguidade entre profissionalismo e proletarização (Oliveira, 2010), é uma forma de pensar tal relação pela perspectiva dos trabalhadores. As políticas de valorização e qualidade se dão em formulações teóricas e legislativas, mas é no interior de mobilizações concretas de agentes objetivos que elas se consolidam e se implementam. Os sindicatos, como agentes coletivos de representação, colocam luz e sombra em aspectos próprios da relação entre valorização e qualidade. Para aproximar o olhar sobre esses aspectos, passamos a uma mirada sobre os documentos da CNTE.

\section{O debate sindical e a valorização dos professores}

O papel dos sindicatos de professores no embate sobre o conteúdo das políticas educacionais tem sido apontado como uma característica do sindicalismo docente (Ferraz; Gindin, 2014; Gindin, 2015) que se articula à tradicional agenda corporativa. Considerar a relação entre qualidade da educação e valorização de professores pressupõe pensar o quanto a luta contra a proletarização - atividade essencialmente corporativa - encontra a construção da profissão - consolidação de um saber especializado e de controle da atividade laboral que confere qualidade à ação - e conduz as disputas das políticas educacionais pelas entidades sindicais. Ou seja, não cabe apenas uma defesa utilitarista de que é preciso valorizar o profissional como se isso representasse automaticamente a ampliação da qualidade da educação. Essas são facetas efetivamente imbricadas, mas que se relacionam de maneira mais complexa do que como inputs e outputs.

O olhar sobre a questão com base nos "planos de lutas" da CNTE num percurso histórico permite observar a complexificação das facetas. Assim, procurou-se categorizar as reivindicações em dois blocos por meio do mapeamento do conjunto dos documentos de congressos: lutas corporativas e lutas educacionais. O bloco corporativo incluiu carreira, remuneração, jornada e condições de trabalho, e o das lutas educacionais englobou política educacional ampla, projeto pedagógico, formação docente, gestão e financiamento da educação. 
Tabela 1 - Quantidade de reivindicações por congresso e tipo CNTE - 1990-2017

\begin{tabular}{|c|c|c|c|c|c|c|c|c|c|c|}
\hline Bloco & Categoização & 1990 & 1991 & 1993 & 1997 & 1999 & 2005 & 2011 & 2014 & 2017 \\
\hline \multirow{4}{*}{ Corporativo } & Carreira e remuneração & 1 & 2 & 2 & 4 & 6 & 2 & 2 & 5 & 2 \\
\hline & Piso salarial & & 1 & & & 2 & 1 & 8 & 2 & 2 \\
\hline & Condições de trabalho & & & & & & & 2 & 3 & 4 \\
\hline & Jornada & & 1 & & & 1 & & & & \\
\hline \multirow{8}{*}{$\begin{array}{c}\text { Lutas } \\
\text { educacionais }\end{array}$} & Educação pública & & 1 & 2 & 1 & 1 & 4 & & & 1 \\
\hline & $\begin{array}{l}\text { Financiamento da } \\
\text { educação }\end{array}$ & & 1 & 2 & 2 & 5 & 5 & 2 & 6 & 4 \\
\hline & Formação & & 1 & & & & & & 1 & 2 \\
\hline & Gestão democrática & 1 & 4 & 3 & 3 & 3 & 2 & & 3 & 2 \\
\hline & Política educacional & 2 & 5 & 8 & 5 & 5 & 4 & 7 & 14 & 4 \\
\hline & Políticas públicas & & & & & & & & 4 & \\
\hline & Projeto educacional & 2 & 1 & 5 & 1 & 2 & 4 & & & 2 \\
\hline & TOTAL & 6 & 17 & 22 & 16 & 25 & 22 & 21 & 38 & 22 \\
\hline
\end{tabular}

Fonte: Congressos da Confederação Nacional de Trabalhadores da Educação (CNTE); dados organizados pelos autores. Nota: O intervalo entre os congressos variou ao longo do tempo, por questões que não cabem neste artigo.

Os itens que se referiam especificamente às estratégias sindicais foram retirados da Tabela 1, na qual se observa que o número de lutas/reivindicações ao longo dos congressos cresce, ainda que não seja de modo linear. O tratamento dos temas vai exigindo mais especificações e, portanto, a perspectiva das lutas vai tornando-se mais complexa e especializada. Em um primeiro olhar, pode-se identificar que o que denominamos lutas corporativas ocupa uma proporção menor das reivindicações e regularidade. Por exemplo, o tema carreira e remuneração, conforme esperado, aparece em todas as edições. Os tópicos que abordam as condições gerais da educação têm maior presença numérica, mas também variam mais em relação à conjuntura. Destaca-se o tema da gestão democrática com uma regularidade importante. Uma hipótese é que, por um lado, a questão é crucial para a organização da educação, tanto que é um princípio constitucional de organização da educação pública; por outro lado, é um tema de fronteira entre o corporativo e o educacional. Considerando os debates sobre a necessidade de a profissão docente recuperar a capacidade de tomada de decisão e autonomia, ou o controle sobre a codificação de seu trabalho nos termos de Mehta (2013), a gestão coletiva da vida escolar é um elemento relevante para a disputa sindical.

Paradoxalmente, essa busca de autonomia, via controle democrático da gestão - que implica controle das condições de trabalho, visto que contrapõe a autonomia da escola à heteronomia ao sistema -, ofusca o debate sobre formação. Talvez aqui se revele um dos limites da ambiguidade entre profissionalismo e proletarização. 
Ainda que pautado pela luta da valorização docente, enquanto princípio constitucional da política educacional, o sindicalismo retira sua força política da capacidade de mobilização de sua base real - professores que, ao longo do tempo, tiveram os mais diferentes padrões de formação, nem sempre correspondentes ao nível superior. Contradição que se intensifica nas distintas etapas de ensino a que estão ligados.

Para aproximar a visão das demandas sindicais em relação às condições de produção da escola e da profissão, observe-se as reivindicações do Congresso de 1991. O primeiro congresso da CNTE é de 1990, porém este é o Congresso da Unificação, com um documento mais rico em elementos de organização interna. Optou-se, como antes mencionado, pela análise das lutas educacionais em 1991, quando elas já apresentavam uma formulação mais ampla.

\section{Quadro 1 - Eixo de lutas educacionais nas resoluções do Congresso da CNTE - 1991}

\begin{tabular}{|c|c|}
\hline Eixo & Congresso 1991 \\
\hline \multirow{2}{*}{ Carreira e remuneração } & $\begin{array}{l}\text { Valorização dos trabalhadores em educação, regulamentando } \\
\text { suas conquistas constitucionais imediatamente. }\end{array}$ \\
\hline & Plano Nacional de Carreira Profissional. \\
\hline Piso salarial & Piso Profissional Salarial. \\
\hline Jornada & $\begin{array}{l}\text { Jornada de trabalho com } 50 \% \text { de horas-atividades para todos } \\
\text { os membros do magistério que atuem do pré-escolar ao } 2^{\circ} \text { grau. }\end{array}$ \\
\hline Educação pública & $\begin{array}{l}\text { A CNTE deverá organizar uma campanha nacional contra as } \\
\text { medidas autoritárias, demagógicas, propostas pelo governo para } \\
\text { a área de educação. Essa campanha é parte fundamental do } \\
\text { movimento em defesa da escola pública e devera ter como eixo } \\
\text { central: }\end{array}$ \\
\hline $\begin{array}{l}\text { Financiamento da } \\
\text { educação }\end{array}$ & Por verbas públicas exclusivamente para escolas públicas. \\
\hline Formação & Formação e capacitação dos recursos humanos \\
\hline \multirow{4}{*}{ Gestão democrática } & Conselhos deliberativos e soberanos. \\
\hline & Eleição direta para diretor de escola. \\
\hline & Incentivo de formação dos grêmios livres e estudantis. \\
\hline & $\begin{array}{l}\text { Por eleição direta de diretores de escola, articulada com as } \\
\text { entidades estudantis. }\end{array}$ \\
\hline \multirow{5}{*}{ Política educacional } & $\begin{array}{l}\text { Melhoria da infraestrutura da qualidade dos serviços oferecidos } \\
\text { pelas escolas públicas: construção, manutenção e reforma dos } \\
\text { prédios escolares. }\end{array}$ \\
\hline & $\begin{array}{l}\text { Aquisição de equipamentos e materiais didático-pedagógios } \\
\text { para todas as escolas. }\end{array}$ \\
\hline & Merenda suficiente e de qualidade para todos os alunos. \\
\hline & Por uma LDB democrática e progressiva. \\
\hline & Contra os 200 dias letivos. \\
\hline Projeto educacional & $\begin{array}{l}\text { A CNTE deverá, imediatamente, aprofundar junto as afiliadas, } \\
\text { discussões sobre concepções de escola, escola unitária, passando } \\
\text { também pela discusssão da grade curricular, politécnica, etc. }\end{array}$ \\
\hline
\end{tabular}

Fonte: CNTE (1991). 
Em termos corporativos, a afirmação da profissão se manifesta na chave da valorização, dando destaque à necessidade de efetivar os mecanismos previstos na Constituição de 1988 relativos a carreira e piso profissional. Note-se que a pauta da jornada coloca luz sobre um tema importante para pensar a qualidade do ensino e a natureza do trabalho docente, a hora-atividade, que tem uma relação direta com as possibilidades de planejamento e, portanto, de controle desse trabalho. Em termos de lutas educacionais, outrossim, a natureza do trabalho docente no âmbito da formação não se apresenta com força, ao contrário, a afirmação da profissão tem uma formulação muito geral de "formação e capacitação de recursos humanos".

O Congresso de 2017, incluído nesta análise por ser o último, ocorre em um contexto de perda de direitos, marcado pela austeridade fiscal e pela aprovação da Emenda no 95/2016, que induziu fortemente estados e municípios a interromperem políticas de valorização. O Quadro 2 retrata a categorização das reivindicações. Observe-se que, em termos corporativos, a inclusão de um conjunto de demandas de condições de trabalho revela as tensões que os profissionais da educação vivem na escola. Por exemplo, a questão da gestão democrática, fundamental desde o início dos debates, agrega a explicitação da luta contra o assédio moral.

A discussão sobre a jornada e a formação de professores não aparece. De certa forma, esses temas podem ter sido incorporados à luta pelo cumprimento do Piso Salarial Profissional Nacional (PSPN). Aqui, há uma tensão importante na ideia de profissionalização sustentada pela formação específica de professores. O PSPN foi definido tendo como parâmetro o nível médio na modalidade normal, posição da CNTE que representa um conjunto de trabalhadores componentes das redes públicas, mas que tensiona a ideia de que afirmar a natureza e a complexidade do trabalho docente implica defender o lócus da formação no ensino superior.

\section{Quadro 2 - Eixo de lutas educacionais nas resoluções do Congresso da CNTE - 2017}

\begin{tabular}{|c|c|}
\hline Eixo & Congresso 2017 \\
\hline \multirow{4}{*}{ Condições de trabalho } & Lutar contra o assédio moral nas escolas. \\
\hline & $\begin{array}{l}\text { Lutar em defesa da segurança e promoção da saúde dos } \\
\text { trabalhadores, com a constituição de comissões internas nos } \\
\text { locais de trabalho e no serviço público. }\end{array}$ \\
\hline & $\begin{array}{l}\text { Atuar nas lutas em defesa dos/as trabalhadores/as LGBT em } \\
\text { seus locais de trabalho e contra quisquer discriminações }\end{array}$ \\
\hline & $\begin{array}{l}\text { Realizar em nível nacional uma campanha de denúncia sobre } \\
\text { as condições de trabalho e da saúde dos trabalhadores e } \\
\text { trabalhadoras em educação, com o objeitvo de construir novas } \\
\text { propostas para o trabalho decente nas escolas. }\end{array}$ \\
\hline \multirow[b]{2}{*}{ Carreira e remuneração } & $\begin{array}{l}\text { Lutar contra as restrições impostas pela Lei de Responsabilidade } \\
\text { Fiscal (LRF) ao pagamento de salários nas áreas de saúde e da } \\
\text { educação. }\end{array}$ \\
\hline & $\begin{array}{l}\text { Rejeitar as políticas de valorização profissional baseadas na } \\
\text { meritocracia. Retomada da Lei do Piso em sua base original, ou } \\
\text { seja, garantir a unidade nacional sobre o tema da valorização } \\
\text { profissional articulando a qualifcação da remuneração inicial } \\
\text { com os referenciais mínimos de carreira definidos nacionalmente } \\
\text { por legislação federal. }\end{array}$ \\
\hline
\end{tabular}




\section{Quadro 2 - Eixo de lutas educacionais nas resoluções do Congresso da CNTE - 2017}

\begin{tabular}{|c|c|}
\hline Eixo & Congresso 2017 \\
\hline Piso salarial & $\begin{array}{l}\text { Manter a luta pela implantação imediata e integral da Lei } \\
\mathrm{n}^{\circ} 11.738 \text { e mobilizar a cateria pela regulamentação do Piso } \\
\text { Salarial e das Diretrizes de Carreira para todos os prifissionais } \\
\text { da educadção. }\end{array}$ \\
\hline Educação pública & $\begin{array}{l}\text { Mobilizar a sociedade com vistas à ampliação do direito à } \\
\text { educação pública, de qualidade social, inclulsiva, democrática, } \\
\text { laica, de tempo integral, através de mais financiamento público } \\
\text { (10\% do PIB para a educação pública), da gestão democrática e } \\
\text { da valorização dos educadores. }\end{array}$ \\
\hline \multirow{4}{*}{$\begin{array}{l}\text { Financiamento da } \\
\text { educação }\end{array}$} & $\begin{array}{l}\text { Luta pela manutenção e aplicação da Lei nº 12.858/2013 } \\
\text { (recursos petróleo). }\end{array}$ \\
\hline & $\begin{array}{l}\text { Lutar pela regulamentação do Sistema Nacional de Educação, } \\
\text { do Custo Aluno Qualidade (CAQi e CAQ) e de todas as metas do } \\
\text { PNE, valorizando a educação pública. }\end{array}$ \\
\hline & $\begin{array}{l}\text { Garantir a aplicação de verbas públicas para a educação pública } \\
\text { - contra a privatização e a mercantilização da educação. }\end{array}$ \\
\hline & $\begin{array}{l}\text { Garantir que os recursos advindos da Lei } n^{\circ} 12.858 / 2013 \text {, } \\
\text { concernentes à União, sejam imediatamente destinados à } \\
\text { ampliação dos recursos do FUNDEB, compondo a complementação } \\
\text { da União adicionalmente aos "10\%" já repassados pela mesma } \\
\text { para este fim. }\end{array}$ \\
\hline Formação & $\begin{array}{l}\text { Reinvidicar a instituição de uma política nacional de } \\
\text { profissionalização dos funcionários e funcionárias da educação. }\end{array}$ \\
\hline \multirow{2}{*}{ Gestão democrátca } & $\begin{array}{l}\text { Lutar pela democratização dos conselhos de educação (nacional, } \\
\text { estaduais e municipais) com representação dos educadores } \\
\text { públicos. }\end{array}$ \\
\hline & $\begin{array}{l}\text { Lutar pela instituição, fortalecimento e afirmação dos conselhos } \\
\text { escolares autônomos e pela gestão democrática com eleição } \\
\text { direta das direções em todas as escolas públicas. }\end{array}$ \\
\hline \multirow{4}{*}{ Política educacional } & $\begin{array}{l}\text { Lutar contra a reforma do ensino médio, a lei da mordaça e } \\
\text { todas as propostas reacionárias do governo golpista. }\end{array}$ \\
\hline & $\begin{array}{l}\text { Denunciar em nível nacional a condição das infraestruturas dos } \\
\text { prédios escolares e cobrar maiores investimentos para que sejam } \\
\text { feitas as melhorias necessárias. }\end{array}$ \\
\hline & Regulação e fiscalização da educação privada. \\
\hline & $\begin{array}{l}\text { Lutar contra a terceirização e a precarização das condições de } \\
\text { trabalho, contra as Organizações Sociais na educação e contra } \\
\text { quaisquer parcerias público-privadas. }\end{array}$ \\
\hline \multirow[b]{2}{*}{ Projeto educacional } & Lutar contra a militarização das escolas. \\
\hline & $\begin{array}{l}\text { Pela implementação das leis n } 10.639 \text { e n० } 11.645 \text { e em defesa } \\
\text { da regulamentação do Estatuto da Igualdade Racial e do Estatuto } \\
\text { da Juventude. }\end{array}$ \\
\hline
\end{tabular}

Fonte: CNTE (2017)

Os elementos da conjuntura e da disputa do projeto educacional do País são bastante explícitos e transitam desde as condições de oferta das escolas (infraestrutura, financiamento) até aquelas do plano educacional que interessa aos trabalhadores, o que se vê, por exemplo, nas posições sobre os processos de 
militarização ou na defesa da implementação das diretrizes para a igualdade racial nas escolas.

\section{Considerações finais: aproximações ao debate qualidade e sindicalismo docente}

Este artigo não pretende esgotar o debate da agenda sindical, mas inserir na relação entre valorização e qualidade uma dimensão que se afasta das abordagens pragmáticas que tomam o professor como um insumo que precisa ser valorizado para produzir qualidade. A valorização da docência como profissão, em que pesem os debates em torno do conceito, passa pelo reconhecimento da visão que os professores têm sobre o processo educacional, sintetizado em certa medida pelo debate sindical, que reafirma a necessidade de a qualidade ser dimensionada, de acordo com Dourado e Oliveira (2009), em diferentes planos que vão da proteção ao estudante à gestão do sistema. Nesses termos, há um conhecimento específico que é fundamental para a ação docente operar em meio ao conjunto de demandas e de pressões.

A agenda sindical coloca luzes em algumas dessas tensões, por exemplo, a permanente necessidade da gestão democrática e a luta contra seu oposto, as demandas para regular o assédio moral nas escolas. Mas a agenda sindical deixa na sombra alguns elementos, como o caso específico da formação. A pergunta sobre o lócus que define o profissional e assegura a qualidade na educação, ambígua na legislação, entre a formação de nível médio na modalidade normal e a licenciatura, não aparece de forma explícita. A formação, ainda que categorizada como luta educacional, revela-se no interior de um forte limite corporativo. Mesmo quando coloca em cena a reforma do ensino médio, o documento analisado não traz ao palco a questão do notório saber, presente em tal reforma e frontalmente oposto ao conceito de profissionalização docente.

Se as políticas de valorização docente se constituem componentes das políticas de qualidade educacional, e dentro desse marco se articulam como políticas de remuneração, carreira, condições de trabalho e formação, esta última parece ser o elo frágil na pauta sindical. Da mesma maneira, se compreendermos profissionalização como processo de autonomização de um coletivo detentor de conhecimento especializado que consegue exercer controle sobre suas próprias condições de trabalho, o segundo elemento se faz sentir fortemente (gestão democrática, luta contra formas de assédio, oposição à escola sem partido etc.), mas a posse de um conhecimento especializado não tem a mesma ênfase discursiva.

A ambiguidade entre profissionalização e proletarização (Oliveira, 2010) se insinua para o segundo polo, reforçando a ideia de "semiprofissão" de Mehta (2013). Entendemos a complexidade desse paradoxo, pois o polo teórico de proletarização - na agenda sindical - é a luta contra esse processo e não o seu reforço. E, quando se sugere o reforço da "semiprofissão", não se pensa em sinônimo de proletarização. Ao contrário, a dinâmica da luta corporativa e de classe, que está na base do 
movimento sindical, não necessariamente se harmoniza de maneira linear com a profissionalização, no sentido que esse termo tem para a sociologia das profissões - que, muitas vezes, inspira as políticas de valorização. Para tal debate, faz-se necessário um conceitual mais refinado, o que não cabe neste momento. Aqui, apenas se registra que a empiria provoca o campo científico a repensar a relação entre qualidade, valorização e luta sindical.

\section{Referências bibliográficas}

ALVES, T. et al. Financiamento da escola pública de educação básica: a proposta do simulador de custo-aluno-qualidade. Educação \& Sociedade, Campinas, v. 40, p. 1-40, dez. 2019.

BARBOSA, A. Salários docentes, financiamento e qualidade da educação no Brasil. Educação \& Realidade, Porto Alegre, v. 39, n. 2, p. 511-532, abr./jun. 2014. Disponível em: < https://www.scielo.br/pdf/edreal/v39n2/v39n2a09.pdf > . Acesso em: 10 abr. 2016.

BRASIL. Lei no 9.394, de 23 de dezembro de 1996. Estabelece as diretrizes e bases da educação nacional. Brasília. Diário Oficial da União, Brasília, DF, 23 dez. 1996. Disponível em: <http://www.planalto.gov.br/ccivil_03/leis/19394.htm> . Acesso em: 16 dez. 2020.

BRASIL. Lei $n^{\circ}$ 10.639, de 9 de janeiro de 2003. Altera a Lei $n^{\circ}$ 9.394, de 20 de dezembro de 1996, que estabelece as diretrizes e bases da educação nacional, para incluir no currículo oficial da Rede de Ensino a obrigatoriedade da temática "História e Cultura Afro-Brasileira" [...]. Diário Oficial da União, Brasília, DF, 10 jan. 2003.

BRASIL. Lei $\mathrm{n}^{\circ}$ 11.645, de 10 de março de 2008. Altera a Lei $\mathrm{n}^{\circ}$ 9.394, de 20 de dezembro de 1996, modificada pela Lei no 10.639, de 9 de janeiro de 2003, que estabelece as diretrizes e bases da educação nacional, para incluir no currículo oficial da rede de ensino a obrigatoriedade da temática "História e Cultura AfroBrasileira e Indígena". Diário Oficial da União, Brasília, DF, 11 mar. 2008.

BRASIL. Lei no 11.738, de 16 de julho de 2008. Regulamenta a alínea "e" do inciso III do caput do art. 60 do Ato das Disposições Constitucionais Transitórias, para instituir o piso salarial profissional nacional para os profissionais do magistério público da educação básica. Diário Oficial da União, Brasília, DF, 17 jul. 2008.

BRASIL. Lei no 12.858, de 9 de setembro de 2013. Dispõe sobre a destinação para as áreas de educação e saúde de parcela da participação no resultado ou da compensação financeira pela exploração de petróleo e gás natural, com a finalidade de cumprimento da meta prevista no inciso VI do caput do art. $214 \mathrm{e}$ no art. 196 da Constituição Federal; altera a Lei no 7.990, de 28 de dezembro de 1989; [...]. Diário Oficial da União, Brasília, DF, 10 set. 2013. 
BRASIL. Lei no 13.005, de 25 de junho de 2014. Aprova o Plano Nacional de Educação - PNE e dá outras providências. Diário Oficial da União, Brasília, DF, 26 jun. 2014. Seção 1. p. 1.

BRASIL. Lei n 13.415, de 16 de fevereiro de 2017. Altera as Leis n ${ }^{\circ} 9.394$, de 20 de dezembro de 1996, [...]e institui a Política de Fomento à Implementação de Escolas de Ensino Médio em Tempo Integral. Diário Oficial da União, Brasília, DF, 17 fev. 2017.

CAMARGO, R. B. et al. Pesquisa Nacional Qualidade na Educação: problematização da qualidade em pesquisa de custo-aluno-ano em escolas de educação básica. Brasília, DF: Inep/MEC, 2006. 140 p.

CONFEDERAÇÃO NACIONAL DOS TRABALHADORES DA EDUCAÇÃO (CNTE). Entidades filiadas. [2020]. Disponível em: < https://www.cnte.org.br/index.php/ menu/institucional/entidades-filiadas > . Acesso em: $21 \mathrm{dez} .2020$.

CONGRESSO NACIONAL DOS TRABALHADORES DA EDUCAÇÃO (CNTE), 23., 1991. Caderno de resoluções. Olinda: CNTE, 1991.

CONGRESSO NACIONAL DOS TRABALHADORES DA EDUCAÇÃO (CNTE). 33., 2017. Caderno de resoluções. Brasília, DF: CNTE, 2017. Disponível em: < https:// www.cnte.org.br/images/stories/2017/33_congresso_caderno_de_resolucoes_ final_web.pdf $>$. Acesso em: $21 \mathrm{dez} .2020$.

CURY, C. R. J. A qualidade da educação brasileira como direito. Educação \& Sociedade, Campinas, v. 35, n. 129, p. 1053-1066, out./dez. 2014. Disponível em: < https://www.scielo.br/pdf/es/v35n129/0101-7330-es-35-129-01053.pdf>. Acesso em: 21 set. 2020.

DOURADO, L. F.; OLIVEIRA, J. F. A qualidade da educação: perspectivas e desafios. Cadernos Cedes, Campinas, v. 29, n. 78, p. 201-215, maio/ago. 2009. Disponível em: < https://scielo.br/pdf/ccedes/v29n78/v29n78a04.pdf> . Acesso em: 21 set. 2020.

FERRAZ, M. A. S.; GINDIN, J. Sindicalismo docente no Governo Lula: desafios, protagonismo e fragmentação. In: OLIVEIRA, R. V.; BRIDI, M. A.; FERRAZ, M. (Orgs.). O sindicalismo na Era Lula: paradoxos, perspectivas e olhares. Belo Horizonte: Fino Traço, 2014. p. 283-303.

GINDIN, J. Por nós mesmos: o sindicalismo docente de base na Argentina, no Brasil e no México. Rio de Janeiro: Azougue, 2015.

GROCHOSKA, M. A. Políticas educacionais e a valorização do professor: carreira e qualidade de vida dos professores de educação básica do município de São José dos Pinhais/PR. 2015. Tese (doutorado em Educação) - Universidade Federal do Paraná, Curitiba, 2015.

HANUSHEK, E. A. Valuing teachers: how much is a good teacher worth? Education Next, v. 11, n. 3, p. 40-45, 2011. 
HYPOLITO, A. M. BNCC, agenda global e formação docente. Revista Retratos da Escola, Brasília, DF, v. 13, n. 25, p. 187-201, jan./maio 2019. Disponível em: $<$ http://retratosdaescola.emnuvens.com.br/rde/article/view/995/pdf > . Acesso em: 21 dez. 2020.

INCISA, L. Corporativismo. In: BOBBIO, N.; MATTEUCCI, N.; PASQUINO, G. Dicionário de política. Brasília, DF: UnB, 1992.

LAPADAT, J. C. Thematic analysis. In: MILLS, A.; DUREPOS, G.; WIEBE, E. Encyclopedia of case study research. Thousand Oaks, USA: SAGE Publications, 2010. Disponível: <http://dx.doi.org/10.4135/9781412957397> . Acesso em: 21 dez 2020.

MEHTA, J. The allure of order. New York: Oxford University Press, 2013.

NÓVOA, A. Firmar a posição como professor, afirmar a profissão docente. Cadernos de Pesquisa, São Paulo, v. 47, n. 166, p. 1106-1133, out./dez. 2017. Disponível em: <https://www.scielo.br/pdf/cp/v47n166/1980-5314cp-47-166-1106.pdf>. Acesso em: 21 set. 2020.

NÓVOA, A. Os professores e a sua formação num tempo de metamorfose da escola. Educação \& Realidade, Porto Alegre, v. 44, n. 3, p. 1-15, set. 2019. [e84910. Epub 12-set-2019] Disponível em: <https://seer.ufrgs.br/ educacaoerealidade/article/view/84910 >. Acesso em: 21 set. 2020.

OLIVEIRA, D. A. Os trabalhadores da educação e a construção política da profissão docente no Brasil. Educar em Revista, Curitiba, n. especial, p. 17-35, 2010. Disponível em: <https://revistas.ufpr.br/educar/article/view/20463>. Acesso em: 21 set. 2020.

PINTO, J. M. de R. Uma proposta de custo-aluno-qualidade na educação básica. Revista Brasileira de Política e Administração da Educação, Brasília, DF, v. 22, n. 2, p. 197-227, jul./dez. 2006. Disponível em: < https://seer.ufrgs.br/rbpae/article/ view/18877>. Acesso em: 21 set. 2020.

REIS, B. P. W. Corporativismo, pluralismo e conflito distributivo no Brasil. Dados: Revista de Ciência Sociais, Rio de Janeiro, v. 38, n. 3, p. 417-457, 1995.

TENTI FANFANI, E. La condición docente: análisis comparado de la Argentina, Brasil, Perú y Uruguay. Buenos Aires: Siglo XXI, 2005.

VERHINE, R. E. Levantamento de custo-aluno-ano em escolas de educação básica que oferecem condições de oferta para um ensino de qualidade. Relatório Nacional de Pesquisa produzido para o Inep. 2005.

YANNOULAS, S. C. Feminização ou feminilização? Apontamentos em torno de uma categoria. Temporalis, Brasilia, DF, v. 11, n. 22, p. 271-292, jul./dez. 2011. 
Andréa Barbosa Gouveia, doutora em Educação pela Universidade de São Paulo (USP), é professora da Universidade Federal do Paraná (UFPR), onde atua no Núcleo de Pesquisa em Políticas Educacionais e está credenciada no Programa de Pós-Graduação em Educação, na linha de pesquisa em Políticas Educacionais.

andreabg@ufpr.br

Marcos Alexandre dos Santos Ferraz, doutor em Sociologia pela Universidade de São Paulo (2005) e pós-doutor pelo Centro de Estudos Sociais da Universidade de Coimbra, Portugal, é professor associado no Setor de Educação da Universidade Federal do Paraná (UFPR), do qual também é diretor. Tem experiência na área de Sociologia, com ênfase em Sociologia do Trabalho e Sindicalismo, atuando principalmente nos seguintes temas: sindicalismo docente na educação básica, trabalho docente e política educacional, movimento dos trabalhadores e sociologia do trabalho.

ferrazmarcos@uol.com.br

Recebido em: 29 de junho de 2020

Aprovado em 21 de setembro de 2020 